\title{
Article
}

\section{This is what we do with the rest of the day! Exploring the macro and meso levels of elite golf performance}

Davies, T.C.A., Collins, D., and Cruickshank, A.

Available at http://clok.uclan.ac.uk/15658/

Davies, T.C.A., Collins, D., ORCID: 0000-0002-7601-0454 and Cruickshank, A. ORCID: 0000-0002-8893-2341 (2017) This is what we do with the rest of the day! Exploring the macro and meso levels of elite golf performance. The Sport Psychologist, 31 (2). pp. 117-128. ISSN 0888-4781

It is advisable to refer to the publisher's version if you intend to cite from the work. http://dx.doi.org/10.1123/tsp.2016-0049

For more information about UCLan's research in this area go to http://www.uclan.ac.uk/researchgroups/ and search for < name of research Group>.

For information about Research generally at UCLan please go to http://www.uclan.ac.uk/research/

All outputs in CLoK are protected by Intellectual Property Rights law, including Copyright law. Copyright, IPR and Moral Rights for the works on this site are retained by the individual authors and/or other copyright owners. Terms and conditions for use of this material are defined in the policies page.

\section{CLoK}

Central Lancashire online Knowledge www.clok.uclan.ac.uk

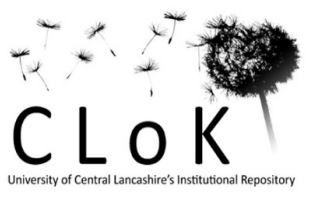


This is what we do with the rest of the day! Exploring the Macro and Levels of Elite

\section{Golf Performance}

9

Accepted author version for:

Davies, T., Collins, D., \& Cruickshank, A. (in press). This is what we do with the rest of the day! Exploring the macro and levels of elite golf performance. The Sport Psychologist. 
Running head: MACRO AND MESO LEVELS OF GOLF

PERFORMANCE

Abstract

19 Despite substantial research in golf on pre-shot routines, our understanding of what elite golfers are or potentially should be focusing on beyond this phase of performance is limited. Accordingly, interviews were conducted with elite-level golfers and support practitioners to explore what golfers are and should be attending to before competition and between shots and holes. Results pointed to a number of important and novel processes for use at macro (i.e., precompetition) and meso (i.e., between shots and holes) levels, including the role of shared mental models across team members. 
Running head: MACRO AND MESO LEVELS OF GOLF

PERFORMANCE

This is what we do with the rest of the day! Exploring the Macro and Meso Levels of Elite Golf Performance

Previous research has outlined a range of valuable mental skills for optimizing golf performance (Hellström, 2009). Notably, a large body of this work has adopted a micro (i.e., short term: immediately around a single shot) focus; primarily on pre-shot routines (Cotterill, 2010). However, while this process is clearly important for elite players, it accounts for very little actual performance time. Indeed, if it takes roughly one minute to perform a pre-shot routine, hit the golf ball, and then react to the shot, players who take 72 shots during a 4 hour round may only be involved in such micro-level activity for 72 minutes. Therefore, to extend theory and practice in elite golf performance, there is a need to explore what elite golfers are and potentially should be focusing their attention on outside of pre-shot and shot execution stages; or, in other words, during the meso (i.e., the rest of the time between shots and holes) and macro (i.e., across the whole round, including preparation) levels of performance.

Interest in the focus and nature of performer attention has a long history in sport (e.g., Garfield \& Bennett, 1984; Loehr, 1994; Ravizza, 1977). Attention has been defined as “what we are thinking about (or not thinking about) or what we are aware of (or not aware of) when we perform activities” (Magill \& Anderson, 2014, p. 201) and studies in golf have largely considered this construct at a micro (or pre-shot) level. Specifically, results from these works have shown that pre-shot routines that are tailored to performers' needs and goals can have a positive impact on performance (Cotterill, 2010; Cotterill, Sanders, \& Collins, 2010; Crews \& Boutcher, 1986; McCann, Lavallee, \& Lavallee, 2001). Due to the small amount of time that a golfer actually spends on a pre-shot routine and swing, however, recent work has reinforced earlier calls (e.g., Hellström, 2009) for greater exploration of attentional patterning at meso- and macro-levels (Davies, Collins, \& Cruickshank, 2014). For clarity, the meso- 
level of golf performance relates to the time in between shots and holes while the macro-level of golf performance relates to the time before and after a round. Indeed, both of these time periods may play a significant role in performance given the potential for maladaptive thoughts in these moments around, for example, tournament expectations, course strategy, past or future shots, tournament position, current score, or an opponent or partner's score (Hayslip, Petrie, McIntyre, \& Jones, 2010). In sum, there is a knowledge gap in the macroand meso-level processes and actions involved in successful elite golf performance.

Considering what we do already know about macro-level processes, pretournament planning has long been identified as important to elite golfers. Indeed, McCaffrey and Orlick (1989) found that general performance strategies are best prepared in advance; a process that, in research with other sports, has been shown to help performers feel more relaxed, prepared, and in control (Blumensein \& Lidor, 2008; Collins \& Cruickshank, 2015; Gould \& Maynard, 2009). Importantly, these outcomes have also been linked to peak performance (Cohn, 1991). As we are not aware of any research that has explored the actual elements of effective macro-planning in elite golf, performers and their support personnel (e.g., coaches, caddies, and psychologists) have therefore presumably approached this challenge using personal experience and social norms of "best practice" and non-peer reviewed sources such as Aitken and Weigand (2007). As such, it is reasonable to suggest that targeted research would help to identify then rigorously evaluate and optimize these macro-level processes.

As well as macro-level factors, Davies, et al. (2014) recently stimulated discussion on meso-level processes in elite golf; or what is done in the broader time periods before and after a swing. This includes the golfer's post-shot routine, their use of time between shots and holes, and their $p^{2}{ }^{2}$-shot routine (i.e., the pre-pre shot routine: the preparation routine engaged before a pre-shot routine, as characterized by a broader and more external focus of 
Running head: MACRO AND MESO LEVELS OF GOLF

PERFORMANCE

attention to collect and interpret information on the shot rather than the priming of the actual shot). Despite these meso-level periods accounting for the bulk of time a golfer will spend on the course, exactly what golfers are or should be doing and thinking in this period has received little attention in literature. In terms of what has been advised, Kirschenbaum, Owens, and O’Connor (1998) previously proposed a pre ${ }^{2}$-shout routine based on four principles. Specifically, personal par involves a player adjusting the expected score on a hole based on handicap; the conservation principle involves the player using more conservative shots where possible; under the wide first principle, the golfer is encouraged to aim for the widest part of fairways and greens; and finally, the safety first principle encourages the golfer to go for safer means of escape if their previous shot puts them in trouble. While face-valid assertions for many, these guidelines are too simple for most if not all elite golfers who normally won't play to a handicap and, should they want to compete at the top of the field, need to play generally more attacking shots, aim at smaller targets, and take more calculated risks. Kirschenbaum et al.'s advice to use these general principles in specific situations is also clearly problematic from an applied stance.

Beyond the golfer's pre ${ }^{2}$-shot routine, an area of further interest at the meso-level of performance is what elite golfers are or should be doing after a shot; in short, their post-shot routine. A post-shot routine includes cognitive and behavioral processes that can help golfers to "put away" a shot, shift attention to the next one, and excel under pressure, although few clear, empirically-based guidelines for this process have been identified in elite golf (cf. Finn, 2009; Hill, Hanton, Matthew, \& Fleming, 2010; Kirschenbaum, 1997; Kirschenbaum et al., 1998). Recent work in bowling has also supported the benefits of post-shot routines. Indeed, while Mesagno, Hill, and Larkin (2015) found no significant gain in performance after a postshot routine was introduced, participants felt that this improved or protected their attentional 
Running head: MACRO AND MESO LEVELS OF GOLF

PERFORMANCE

100

101

102

103

104

control, focus on the task, re-focusing between shots and games, ability to block distractions, attention after an error, emotional control, constructive reflection, confidence, and selfawareness. As the authors pointed out, however, knowledge on post-shot routines across a range of sports requires expansion. In the case of the present paper, exploring meso-level time periods in elite golf may help to identify what is or should be attended to during this process and the perceived impact that these features have on performance.

As further identified by Davies et al. (2014), one particularly important part of macroand meso-level processes in elite golf is the input of the player's support team. Indeed, elite golfers will often work with all members of their support team at some point during the preparation and performance period; usually consisting of a coach, caddie, and psychology specialist. These practitioners can play a significant role in what the golfer attends to (and what they don't) before, during, and after competition, with optimal input from each logically relying on strong and trusting relationships (cf. Hemmings, 2011; Simpson, Bell, \& Flippin, 2011). On top of this, it would seem vital that a golfer and their support team also hold shared mental models (hereafter SMMs) relating to the task (i.e. how the team will respond to task demands), team interaction (i.e. how each individual will contribute to the task alongside others), and team member needs (i.e. how each team member will behave and react) to maximize “on the day” potential and minimize process losses (Cannon-Bowers, Salas, \& Converse, 1993; Davies et al., 2014).

Owing to the fact that the player cannot receive advice from their coach or psychology specialist during play, the direct input of these support team members is confined to the preparation of performance before the tournament starts or between rounds. Somewhat uniquely, however, the player is able to draw on another support team member - the caddie in “real time”. While a caddie's role in supporting a golfer's attention "in play” is apparent, 
Running head: MACRO AND MESO LEVELS OF GOLF

PERFORMANCE

there are a lack of peer-reviewed studies on how this is enabled via macro-level processes (i.e., what the player and caddie do before and after play). Considering broader literature, Aitken and Weigand (2007) have reported on experienced caddies’ perceptions of their roles and contribution to the golfer's performance including the communication process, decision making (including having a game plan and shared goals), barriers to success, and how caddies can help players to switch on and off. As of yet, however, no work has considered the role and contribution of other members of the support team who a golfer will commonly work with during the macro time periods (i.e., a coach and a psychology specialist and what effect this work, in conjunction with the caddie, has on golfers' "in play" attention).

Given the gaps identified in our Introduction, there is a need to expand our knowledge in both the macro- and meso-level processes in elite golf, including the influence of shared mental models between player and support team. In order to create a sufficiently rich and representative picture of these processes, it was essential to explore opinions from not only golfers but also key stakeholders with experience of working with a number of golfers. Thus, the purposes of this paper were threefold. Firstly, we aimed to identify what is perceived to constitute effective planning at the macro-level (i.e., pre-round) of performance by elite golfers and support team members, including how this impacts on a golfers' attention at the macro- and meso-level of performance (i.e., the time between shots, including the lead up to the pre-shot routine). Second, we aimed to explore what elite golfers are and potentially should be focusing their attention on at the meso-level of performance through the same multiple perspectives. Finally, we intended to explore if and how SMMs between player and support team were perceived to influence the golfer's attention and thinking at both macroand meso-levels. 
Running head: MACRO AND MESO LEVELS OF GOLF

PERFORMANCE

\section{Research Philosophy and Strategy}

Reflecting the applied basis of our aims and desire to develop practically-meaningful knowledge, our approach in this study was driven by a pragmatic research philosophy. Under this perspective, methods are selected on their suitability for answering the research questions and not dictated by one particular epistemological view (Giacobbi, Poczwardowski, \& Hager, 2005). Indeed, our aim was not to develop generalizable "truths” (as per extreme positivism) or an interpretation that couldn't be deemed more or less accurate than others (as per extreme relativism) but rather, to provide practically meaningful insights on a particular applied challenge; as supported by our own experience of consulting and performing in elite golf (the first author is a PGA professional with extensive coaching and playing experience and the other authors have consulted in elite-level golf; Giacobbi et al., 2005). Given our aim to explore perceived best practice in an understudied area, a qualitative research strategy was thereby adopted (Denzin \& Lincoln, 2008). Importantly, qualitative study aims to generate a useful map of the world rather than a correct one (Strean, 1998). In line with our pragmatic philosophy, this approach also allowed us to probe perceptions in particular detail (Denzin \& Lincoln, 2008).

\section{Participants}

Data were collected from sixteen participants which included four professional golfers, four coaches, four caddies, and four psychology specialists. The majority of participants (two caddies, three players, four coaches, and four psychology support providers) were purposively sampled through the personal contacts of the lead researcher, with all additional participants recruited through snowball sampling (Frost, 2011).

All of the players held playing rights on tours across various levels. Specifically, one player held playing rights on the EuroPro Tour, one held a European Tour card, and two were 
Running head: MACRO AND MESO LEVELS OF GOLF

PERFORMANCE

172

173

174

175

176

177

178

179

180

181

182

183

184

185

186

187

members of the European Seniors Tour (one of these had played on the European Tour for over 20 years). To be included in the study, players were also required to have a minimum of 3 years' experience of playing professional golf. Players’ ages ranged from 26-54 ( $M=40$, $S D=14.50)$ with experience as a full-time playing professional ranging from 3-29 years ( $M$ $=11.75, S D=11.70)$.

For support team participants (i.e., the coaches, caddies, and psychology support providers), inclusion criteria required at least 5 years' experience working with professional players who had competed at national or tour level. Coaches were also required to be PGA qualified while psychology support providers were required to be educated to a minimum of degree level (two of the four were chartered sport and exercise psychologists through the British Psychological Society) and be working, or have worked with elite amateur or professional golfers. All of the support practitioners had worked in elite golf for between 5 and 27 years $(M=11.25, S D=7.15$ years $)$, had experience working with multiple golfers (the least experienced had worked with four professional golfers), and were aged between 23 and $55(M=37.75, S D=7.10)$.

\section{Procedure}

Prior to each interview, participants were sent information about the purpose of the study and a copy of the interview guide. Based on our pragmatic approach (Giacobbi et al., 2005) and the study's explorative nature, this guide consisted of open-ended questions that elicited responses on broad areas of relevance informed by the literature and our own applied experience. Specifically, these questions firstly addressed attentional focus over the course of a tournament (including pretournament, pre-shot, post-shot, in between shots and holes, and post-round). More specifically, example questions included: What do you/what do you want your players to focus on before a tournament, a round, and a shot? What do you/what do you 
Running head: MACRO AND MESO LEVELS OF GOLF

PERFORMANCE

want your players to focus on after a shot? Is there a preferred sequence or series of steps? Is there a rhythm to this per shot, hole, or round? What support do you get/give during a tournament and round? The interview then secondly sought to identify if and how players prepared for required shifts in attention, strategies employed while playing to effectively shift attention, and the variability of attentional focus (e.g., any differences in what players focused on when playing well versus poorly). Here, example questions included: Do you train or practice for shifts in attention or focus and refocus? If so, how? What strategies do you employ or suggest to shift attention correctly whilst playing? Do these processes vary? If so, when and how? Built around these core questions, follow-up probes and prompts were also developed to clarify and elaborate on key points and to support consistency across participants in terms of topics covered (Patton, 2002). However, these probes were different between participant role reflecting their differing expertise and inputs. Pilot interviews were carried out with one PGA professional (a full-time player) and one PGA coach to assess the content, clarity, and coherence of the interview guide (no changes were made from this process). All interviews with the main participants were then conducted by the first author at a convenient place and time (in most cases, the facility where each participant worked) and lasted between 30 and 60 minutes $(M=41, S D=8.20)$. Ethical approval was granted from our institution's ethics committee, confidentiality assured, and informed consent given by all participants.

\section{Data Analysis}

Given the lack of prior research in our focal area, an inductive content analysis was deemed appropriate (Côté, Salmela, Baria, \& Russell, 1993). Led by the first author, this analysis followed three key phases: preparation, organizing, and reporting. In the preparation stage, interviews were transcribed ad verbatim then emailed to each participant to ensure that 
Running head: MACRO AND MESO LEVELS OF GOLF

PERFORMANCE

the answers given at interview accurately and fairly represented their views; no changes were requested through this process (Sparkes \& Smith, 2009). Following this, the first author read each transcript several times to optimize familiarity and understanding (Côté et al., 1993). In the organizing phase, qualitative analysis software (QSR NVIVO 10) was used to transform raw data units into thematic hierarchies. This process involved grouping data into themes (named using content-characteristic words) and constantly comparing these themes and their constituent data to establish distinct factors (Corbin \& Strauss, 2008; Côté et al., 1993). This abstraction process continued as far as possible without losing the overall meaning of themes. Finally, higher order themes were generated to provide an overall account of the data.

\section{Trustworthiness}

As the process and outcomes of interviews are shaped by the level of trust and rapport with participants (Sparkes \& Smith, 2009), these elements were enhanced through: (a) prior investigation of all interviewees' careers to convey appreciation of their history and situation, including their current performance level and achievements to date; and (b) knowledge of and empathy with the various roles and demands in elite golf due to the first author's experience as a PGA professional coach and player in PGA events. A particularly high level of rapport was evident with six participants, with these individuals remaining to discuss contemporary issues in golf after the formal interview was finished. Subsequently, four of the participants contacted the lead researcher for feedback on the overall results of the study.

Trustworthiness of the analytical process was also addressed. Specifically, constant comparison (Corbin \& Strauss, 2008) ensured that interpretations of the data were continually re-evaluated and reasserted. Further, the second author reviewed meaning units coded by the first author from an early interview and then assessed the labels given to meaning units from roughly $10 \%$ of all other interviews, including their fit with the overall thematic structure. In 
Running head: MACRO AND MESO LEVELS OF GOLF

PERFORMANCE

the few cases of different views, reflective and critical discussion took place until agreement was reached. To aid the first and second authors' awareness of their interacting assumptions and a full critique of developing themes, the third author was also a critical friend throughout (Faulkner \& Sparkes, 1999). Finally, each participant was asked to check their transcribed interview (as per the Data Analysis section) followed by phone calls and emails to discuss our interpretation of their quotes used in this report. This process revolved around gaining assurance over our accuracy, balance, fairness, and respect (Sparkes \& Smith, 2009).

\section{Results}

The aims of this study were to: (a) identify what constitutes effective planning at the macro-level (i.e., pre-round) in elite golf and how this impacts on golfers' attention at the macro- and meso-levels of performance (i.e., the time in between shots, including the pre ${ }^{2}$ shot routine); (b) explore what elite golfers are and potentially should be focusing their attention on at the meso-level of their performance; and (c) explore if and how SMMs between the player and their support team influenced golfers' attention and thinking at macro- and meso-levels. Table 1 shows the processes and actions of players and their support teams at both macro- and meso-levels, as well as their perceived impact on the focus and nature of player attention. While not a primary focus of this study, Table 1 also details the perceived impact of macro- and meso-level processes and actions on other reported psychological factors.

Due to the limitations of space, it is not possible to provide supporting quotes for all of the identified themes in Table 1. As such, we now focus on a combination of themes that address the study's aims, were considered to have the broadest impact on players' attention (as indicated by superscript numbers in Table 1), and which tap into areas underdeveloped in the literature. Reflecting the order of events at a golf event and aims of this study, identified 
Running head: MACRO AND MESO LEVELS OF GOLF

PERFORMANCE

macro-level processes and actions are presented first. This is then followed by key mesolevel processes and actions before evidence on the impact of SMMs. Quotes from players are denoted by "PL”, coaches by “CO”, caddies by “CA”, and psychology support providers by “PS".

\section{Macro-level Processes and Actions}

Five key themes were found in relation to macro-level (i.e., pre-round) processes and actions that were perceived to positively impact on player attention. These were: preparation of course strategy, development/refinement/rehearsal of meso-level routines, support team carrying out off-course tasks for player, consistent preparation routines, and support team reinforcement of player abilities and approach. While the latter four of these themes were clearly important, such approaches are relatively self-explanatory and confirm findings from previous research across other sports. Based upon its perceived scale of impact during competition (or at the meso-level) and the frequency on which it was discussed, we therefore focus primarily on preparation of course strategy.

Indeed, all participants noted the role that thorough preparation of course strategy had in shaping the focus and nature of player attention during competition. Unsurprisingly, team members had varying inputs on the preparation of course strategy based on the player's needs and team dynamics. For example, often the coach, caddie, and psychology specialist were all involved in this process, whereas sometimes this was carried out by the player and caddie, or just the player. Despite the different contributions from team members, there was consensus that a key job ahead of an event was to prepare the strategy that would be focused on during play; thus giving the golfer a more holistic focus during their pre $^{2}$-shot routine:

[Before the tournament we work on] ... where they want to be hitting from the tee, so looking to focus on an area and what club they require to hit to that area. [So the 
Running head: MACRO AND MESO LEVELS OF GOLF

PERFORMANCE

292

293

294

295

296

297

298

299

300

301

302

303

304

305

306

307

308

309

310

311

312

313

314

315

focus is on working out] a specific yardage and putting plans in place so that they’ve got an opportunity to focus on [pre-planned] golf shots [during competition] rather than technical thoughts of where their golf swing is (CO1).

Reflecting upon the use of the pretournament strategy in play, players and caddies also noted how this up-front plan would be used to consider how they should navigate certain shots and factors such as "no go” areas, hazards, and slopes. Having recognized and evaluated these factors before the tournament started, the player's cognitive load during play was therefore proactively managed; thus helping the player to make “cleaner” in-play decisions:

[The pretournament plan] gives them a focus [in play] ... Get it to that area and then once they approach that area they then can go, “right, ok, I know which area I need to put this in [next] for certain pin positions”. So [due to] the preparation, a percentage of it [i.e., the meso-level thinking and acting] is done (CO1).

A major part of preparing the course strategy involved the caddie arriving before the first practice round to begin preparation. As well as optimizing the accuracy of the final strategy - through the caddie adjusting for "at the event” or "on the day" contextual factors (e.g., course conditions) - this also allowed the player to then use practice rounds for testing and tweaking course strategy. Indeed, players widely felt that such fine tuning was their primary aim in practice days; important in that they would then have a clear aim for each shot and, as a result, be less likely to have to make ad hoc decisions in play. In short, they were certain of the shots that they were likely to hit on each hole before the round had started, thus allowing them to channel attention on the most appropriate things at the most appropriate time while keeping resources in reserve to handle the dynamic demands of competition (e.g., changes in weather, having to chase a score, and not hitting the optimal target with their shots). Importantly, this process was not wholly prescriptive (e.g., having written down what 
Running head: MACRO AND MESO LEVELS OF GOLF

PERFORMANCE

club to hit from each tee) but involved picking out certain predetermined areas to hit to on each hole:

I will know that I will have to hit it in certain areas. ... I will try to pick gaps and plot my way around [during the practice days].... . [Then] on the day I'll pick the club to hit that area .... [It means] I will roughly know what club it is going to be; obviously I don’t know exactly until I get there, but I have a pretty good idea (PL3).

Supporting this process, a psychology specialist (PS1) described how the plan could then be “condensed down” in to "one sentence on [each hole with] how to get to the green and create a chance, [with] the key words highlighted in red”. This would then be placed on a laminated card and given to both the player and caddie for reference during the round.

A further aspect of reported importance was preparing for course specific challenges; a process that could start in the weeks building up to an event. Similar to the impact of the caddie's advanced planning of the course strategy, such specificity helped to reduce the need to plan and execute unfamiliar shots in play (as well as optimize confidence in one's ability to perform anticipated shots). PL2 believed that this process should be continued up until teeing off: "on the range, again it will be what we are going to face so obviously we go through the shots required [on the course]”. This was supported by CO4 who felt that a warm-up should involve "a physical warm-up, some kind of swings to loosen up, then from that point forward you really want to be hitting the type of shots you are going to have to play”. To reiterate, a primary aim of this process was to have identified and practiced the type of shots required for the course so that "on the spot" decisions were minimized in play. For example, participants suggested that this could be aided by playing the first four holes on the range: "You know the shots you are going to face [from pretournament plans] . . . so if the first is a par 5 we'll hit 
Running head: MACRO AND MESO LEVELS OF GOLF

PERFORMANCE

driver, 3 wood, and a wedge” (PL2). CO4 also felt that ecologically-valid practice was vital, including hitting in different directions on the range to simulate different wind conditions. As the final sub-theme in preparing course strategy, participants discussed the important role of contingency strategies; in other words, knowing why, when, and how the strategy may change. Any decision to alter the pretournament plan was based on two main factors: a player's standing in the tournament or weather conditions. For example, a player's position in the event shaped how aggressively or conservatively they approached "risk and reward holes”, with most preparing for both eventualities: "I will play two balls [in practice rounds] and play the safe and the aggressive options . . . and see how they actually work out” (PL3). PS4 suggested that one's standard of play on the day could also be a deciding factor for the risk and reward balance. As such, it was important to have considered both variations of strategy (i.e., the aggressive and conservative shots) to make it easier for players to make shot selections in play; once again emphasizing the importance of planning "up front” for the management of attentional resources during competition:

[There may be] two options off the tee, one option might be to be aggressive and hit driver, the other option might be four iron in to position . . . . If they are hitting their driver well [on the day] then they will probably hit driver, [but] if you are not quite feeling confident then at least you have the backup plan [i.e. four iron for position]. Sometimes the backup is more important than the plan for when you are ripping it, that's the thing that keeps you in the tournament. (PS4)

As noted above, participants also felt that environmental factors (especially wind conditions) needed to be considered. For example, while preparing for the Senior Open, PL4 stated: If there is no wind [then] certain bunkers might be in play so you hit a two iron; if it is down wind you can knock it over them with driver, or into the wind you can't reach 
Running head: MACRO AND MESO LEVELS OF GOLF

PERFORMANCE

with driver ... I had got a feel for the course off the tee [so] I was quite comfortable [in the event] with how I was going to play [each shot].

Once again, therefore, the macro-level planning for variations in strategy before play was felt to manage cognitive load at the meso-level of performance, as well as direct attention to the most relevant factors at any given point in a round.

\section{Meso-level Processes and Actions}

Addressing the second aim of this study, three themes were found in relation to what players are or should be focusing on at the meso-level of performance (i.e., the time between shots and holes, including the lead up to a pre-shot routine). These were a post-shot routine, pre $^{2}$-shot routine, and the caddie contributing to meso-level planning processes.

Post-shot routine. When asked what should be done after a shot in competitive play, participant responses coalesced around five sub-themes. Firstly, participants described how immediately after a shot they would expect some kind of reaction, especially if the shot was a bad one. This ranged from "a lot of that [slamming the club] into the bag or club thrown at the bag" (CA3) to "twirling the club after a good shot" (CO2). PS1 also felt that this instant response was useful: "get a reaction, whether it is anger, technical; get shut of that reaction from the last shot". In sum, dealing with emotion, whether "positive” or "negative”, was perceived to allow golfers to direct their attention appropriately later in the post-shot routine.

The second step of the post-shot routine related to considering the reasons behind the shot outcome. Highlighting the permanence of this reflection and reasoning process, CA4 noted: "there will always be a post-mortem after a shot whether it is good or bad". Further, CA4 described how caddies often aided the post-shot analysis; something which also helped to develop player-caddie understanding and support latter stages of the post-shot routine: 
Running head: MACRO AND MESO LEVELS OF GOLF

PERFORMANCE

Sometimes he will hit a shot that might end up really well but he will say "I took a little bit [of distance] off that” ... . [It will have been a] club that we have talked about and agreed but inside his head he has thought "I will take a little bit [of distance] off it” .... Wherever the ball has ended up we will discuss [the shot].

Unsurprisingly, a similar process was described after poor shots; for example, PL2 reported that "we might have a little chat about it; say if ... it was probably the wrong club to hit".

For some players, but certainly not all, identifying the reasons for a poor shot led to rehearsal of a corrected swing; although all agreed that competition "was not the time to disassemble the golf swing” at the expense of having "one thought or corrected feeling” (CO4).

After reflecting on a shot, participants commonly discussed the confirmation/revision of mental models to assist in planning for subsequent shots. This included directing attention towards how well the player was striking the ball, the distance the ball is travelling, or other environmental factors such as how far the ball is running on the ground or the strength and direction of the wind. CA4 offered an example of such alteration in work with a new player: Sometimes he will hit a shot that might end up really good but he will say "I took a little bit off that” and that was what we are working on [in our discussion post-shot], because he will hit a club that we have talked about and agreed ... . [Understanding how he plays] is still a learning curve .... Wherever the ball has ended up we will discuss it and how can we improve it [i.e., our decision making] going forward. Once mental models had been confirmed or revised, the next element of the post-shot routine was acceptance of the shot outcome. The purpose of this stage was to help the player move on from the previous shot (whether good or bad) and keep their attention in the present. As CA1 stated: "I've seen players two holes down the line and they are still hitting bad shots because they are thinking about that [last bad] one”. Similarly, PS4 felt that acceptance was 
Running head: MACRO AND MESO LEVELS OF GOLF

PERFORMANCE

410

vital in moving on from previous shots: "if you have hit a poor shot one of the factors I want them to have is acceptance ... if you can’t accept it you can’t move on” (PS4). Participants then discussed how the final element of a post-shot routine should be for players to neutralize their focus and dissociate from performance. This was perceived to help protect the player from overthinking past or future events; in short, getting lost in outcomes, evaluation, and uncertainty. Indeed, PS4 felt that it was important to focus on "anything but the performance" after a shot. This was supported by CO4:

While you are sort of not engaged directly in the shot or preparation for the shot it's nice to leave the [mental] competitive zone. Then you are not dwelling on things which have happened prior, or trying to sort of second guess what is coming up, or what you need to be doing, or what so and so is doing, or if you need to shoot a certain score. I think that works more efficiently.

Notably, all participants felt that the ability to dissociate from performance between shots and holes was aided by the caddie: "My caddie is quite good in that sense . . . . He’s very chatty, quite loud, thinks he’s quite funny, he'll just go off on one and tell a story” (PL2). Indeed, filling time between shots and holes with conversation with the caddie was perceived to help limit the influence of irrelevant distractions associated with competing in elite golf. It is at this time where CA4 believed caddies "make their money”:

If we don't speak [between shots] and he is thinking about 'if I hole this [putt to make a birdie]' I will be three behind', it is really important to get them totally away from the golf course. What did they do last night? What are they doing on their week off? . . It is really important to get them to switch off otherwise I imagine by the time they get to [the] 9 [ $^{\text {th }}$ hole] they would be absolutely [mentally] obliterated.

Pre $^{2}$-shot routine. Following the post-shot routine, participants reported on a process 
Running head: MACRO AND MESO LEVELS OF GOLF

PERFORMANCE

to return from a dissociative focus and move back into planning for the next shot (i.e., before starting their pre-shot routine). Termed in this study as the $p^{2} e^{2}$-shot routine, the first part of this process was bringing attention back to golf at the appropriate time. There was consensus that the pre ${ }^{2}$-shot routine should begin sometime before the player arrived at the ball but not necessarily triggered by a rigid distance. Indeed, while some were slightly more specific than others (e.g., "I would want someone to start maybe 20 yards behind the ball”: PS2), the exact starting point varied in relation to factors such as player and support team preference or the perceived challenge of the next shot. For example, if the ball was in the trees rather than the fairway then the routine and decision making process may be started earlier. Offering some general guidance, PS4 suggested that a good starting point for the pre $^{2}$-shot routine may be when players have split from their playing partners and informal conversation has ended; at this point, players might then enter "your own little bubble, I call it a shot bubble sometimes . ... My only focus [now] is to make great decisions here and execute with commitment”. Once the player's attention was back on their performance, participants felt that they should then focus on collecting, receiving, and processing shot information. This systematic process was felt to ideally start before the player reached the ball and could include: walking past distance markers, assessing the lie, sighting the target, and feeling the wind strength and direction. At the ball, players then received further information from the caddie based on a consideration and adaptation of the course strategy developed pretournament. Indeed, due to the dynamic nature of tournament golf, no amount of up-front planning could remove the need to adapt a plan on at least some occasions; such as responding to changes in the weather. Beyond the level of individual shots, participants also reported that such adaptation could be more complex and may involve changes to the strategy for a number of holes, especially if "you are coming close to the cut line, or you have to attack or defend" (CA3). 
Running head: MACRO AND MESO LEVELS OF GOLF

PERFORMANCE

As the final part of the pre $^{2}$-shot routine, participants commonly described the value

459

460

461

462

463

464

465

466

467

468

469

470

471

472

473

474

475

476

477

478

479

480

of committing to a decision. Indeed, while the caddie had considerable influence throughout the pre $^{2}$-shot routine up to this point, responsibility for the shot in this finally stage shifted entirely to the player. Accordingly, the caddie's role was felt to become one of optimizing the player's confidence, even if they did not entirely agree with their decision: "he's the boss ... [and will make all every final call] "unless it was suicidal” (CA3)

Caddie contributing to meso-level processes. The third aim of this study was to identify if and how SMMs between golfer and their support team influenced attention at macro- and meso-levels. As suggested by many of the quotes presented thus far, the greatest impact of SMMs was found at the meso-level between players and caddies. Indeed, these quotes have indicated how such SMMs contributed to players' decision making, particularly in the pre ${ }^{2}$-shot routine and the reflection and reasoning part of the post-shot routine. As such, we conclude the Results section by providing a description and supporting quotes for the remaining themes listed under caddie contributing to meso-level processes in Table 1.

One of the most impactful actions of the caddie on player attention at the meso-level was managing the performance environment. Specifically, participants described how the caddie carried out tasks such as management of the crowd, being aware of the pace of play, and being aware of scoreboards; all working to manage the player's attentional focus and load. Regarding the latter, team member mental models were important in underpinning how and when caddies used scoreboard information. For example, the general consensus was that players should “ignore leader-boards as it doesn’t do them any good” (PS2). Team member mental models therefore allowed players to task the caddie with assessing leader-boards and trusting them to decide when to supply information about one's standing in the tournament: 
For me, if you get to the $18^{\text {th }}$ tee and you have a two shot lead on a par five you'd just hit an iron off the tee wouldn't you? That would be my job [i.e., to know the position in the tournament] and point that out.

Participants also revealed how caddies helped to manage the player's attentional focus and load during play by contributing and discussing shot information in the $\mathrm{pr}^{2}$-shot routine. Underpinning this process was caddie knowledge of the player and their game. As suggested by the earlier quote on a caddie helping a player to neutralize their attention, it was noted how established team member and task mental models could help players to think more effectively during meso-level phases; in sum, the caddie, to some extent, already knew what the player was thinking and could thereby streamline their thinking and decision making processes: I know what he is thinking .... If I get to the ball before him and . . . it's for instance 181 to a back pin with a tiny bit of [head] wind I know straight away he’s going to want to hit 6 iron and I know a little 6 iron going through the wind with no spin is going to go over the green. Seven [iron] probably won't get [all the way] there. So I will change it [i.e., the distance given to the player] from 181 to 178; it's only 3 yards different but in his mind 178 is so much less than 181 and he will hit a 7 iron [to avoid going over the back of the green] ... I know the way he plays and the way he thinks.

\section{Discussion}

The aims of this study were threefold. Firstly, we sought to explore views on what constitutes effective planning at the macro-level in elite golf and how this impacts on golfers' attention at the macro- and meso-levels of. Secondly, we aimed to explore what elite golfers are and potentially should be focusing their attention on at the meso-level of their performance. Finally, we intended to explore if and how SMMs between the player and their support team influenced golfers' attention and thinking at macro- and meso-levels. 
Running head: MACRO AND MESO LEVELS OF GOLF

PERFORMANCE

With regards to our first aim, McCaffrey and Orlick (1989) previously highlighted the importance of pretournament planning in golf, including the development of course strategy.

Although space precludes detailed discussion of all of the stages involved in effective macroplanning as identified in this study, the processes and actions in Table 1 extend McCaffrey and Orlick’s points and offer guidance on specific elements and stages of macro-planning. In particular, our results outline key logistical considerations, guidance for developing, testing, and tweaking course strategy, and the roles and responsibilities of team members. As well as contributing to positive effects pretournament, macro-planning also had a notable impact at the meso performance level; the most common being management of the player's attentional

514 focus and load in play. Indeed, by considering factors like distances, target areas, hazards, 515 slopes, and any contingencies up front, as well as practicing anticipated shots and scenarios in the lead up to the event, this approach was deemed to allow players to manage their attention,

517 in part, through clear objectives and expectations. On a theoretical level, attentional control theory (Eysenck, Derakshan, Santos, \& Calvo, 2007) would posit that macro-level activities can allow for dominance of the top-down, goal-directed attentional system instead of the bottom-up, stimulus-directed system during play. In other words, effective macropreparation can provide players with a continual set of goals to work against over their whole round; thus promoting a task focus and the central executive's ability to inhibit and return attention from threat-related stimuli. Consistent with prior research, freeing up attentional resources by managing cognitive load was felt to allow golfers, when required, to use the stimulus-driven attentional system to selectively focus on important task-relevant and

526 situational factors (e.g., weather or standing in the tournament: Corbetta \& Schulman, 2002;

527 Eysenck et al., 2007). 
Running head: MACRO AND MESO LEVELS OF GOLF

PERFORMANCE

As well as optimizing resources for in-play thinking, effective macro-planning was also felt to support appropriate focus during execution phases. More specifically, by already being familiar and comfortable with adaptations to shot selection and technique ahead of the event, the lure of consciously tweaking technique could then be limited and a more holistic focus promoted throughout performance. Indeed, participants revealed that their macro-plans informed many aspects of their pre ${ }^{2}$-shot routine; something which has been overlooked in prior research (e.g., in the plan element of the PAR model: Kirschenbaum et al., 1998). In short, consideration and adaptation of the macro-plan during shot preparation (i.e. the pre $^{2}$ shot routine) was deemed to help players come to a well-considered decision before entering and committing to their pre-shot routine.

At a meso-level, our findings also shed light on what elite golfers are and potentially should be focusing on in the pre ${ }^{2}$-shot routine as well as the purpose that this routine serves. More specifically, an effective routine was felt to involve the golfer (with the support of the caddie) bringing attention back to golf, collecting and processing task relevant information, considering and adapting course strategy, and then committing to a decision ahead of entering the pre-shot routine. This routine builds upon the previous player-caddy decision making model put forward by Lavallee, Bruce, Gorley, and Lavallee (2002) and Aitken and Weigand (2007) by providing detail on how players and caddies use pre-prepared course strategies and situational factors to make a decision on the next shot and additionally highlights the importance of bringing the player's attention back to golf at the start of the routine.

548 Importantly, the pre ${ }^{2}$-shot routine is conceptually and procedurally different to the pre-shot 549 routine as it relates to shot preparation (i.e., using a broader and more external focus of attention to collect and interpret relevant shot information) rather than the priming of the actual shot (i.e., using a narrower and internal focus of attention: Cotterill, 2010; Cotterill et 
Running head: MACRO AND MESO LEVELS OF GOLF

PERFORMANCE

552 al., 2010). As the pre ${ }^{2}$-shot routine revolved around contextual specificity (i.e., what is the best shot selection for the specific situation against the specific strategy for this hole), it also challenges Kirschenbaum et al.'s advice for golfers to prioritize aiming at widest parts of fairways and greens, playing more conservatively, taking a safety first approach, and playing to a personal par.

Building on Kirschenbaum et al. (1998), Finn (2009), and Mesagno et al. (2015), our results also provide a first, research-based account of what elite golfers deem to constitute an effective post-shot routine. In contrast to Kirschenbaum’s (1997) 4-F model which focused on responses to poor shot outcomes only (the first step being fudge), participants in this study suggested that reacting on some level to all shots was useful. Following this initial reaction, Kirschenbaum stated that golfers should then look to fix the prior swing by making a practice swing. However, to understand what went wrong (or right) with the last shot, our participants first advised a period of reflection and reasoning to identify the most salient features behind the outcome (e.g., strategy error or an effective tweak for changing weather). There was also no consensus on the value of rehearsal swings in a post-shot routine; a finding that resonates with inter- and intra-individual inconsistencies between practice and actual swings shown in recent research (Carson, Collins, \& Richards, 2014). Indeed, while some suggested that the course was no place for technique based thoughts, others promoted focus on a holistic cue to reinforce correct technique (Winter, MacPherson, \& Collins, 2014).

After a fix, Kirschenbaum suggested that golfers should forget their previous shot in a manner similar to the notion of acceptance in this study. However, our findings suggest that

573 there should first be a confirmation/revision of mental models. Specifically, this process was deemed important for preventing a mistake being made twice and assisting in the planning of subsequent shots. Finally, Kirschenbaum's 4-F model proposed that golfers should focus 
Running head: MACRO AND MESO LEVELS OF GOLF

PERFORMANCE

576 positively on the next shot. This is in stark contrast to the finding in our study that players

577 should neutralize their attention at the end of the post-shot routine; a point that is more

578 consistent with other practitioners’ accounts (Aitken \& Weigand, 2007). Indeed, such

579 dissociation was felt to deliver a number of benefits, such as decreasing mental fatigue (in

580 comparison to maintaining an associative focus), helping to stay in the present (Cohn, 1991),

581 and inhibiting distractions (Friedman \& Miyake, 2004). However, while it may be useful to

582 dissociate from performance after a shot, work in other sports has suggested that attentional

583 focus is fluid and influenced by factors such as anxiety, self-efficacy, and task intensity (e.g.,

584 Aitchison, Turner, Thompson, Micklewright, \& Gibson, 2013; Eysenck et al., 2007;

585 Hutchinson \& Tenenbaum, 2007). Thus, dissociating from performance will clearly be a

586 challenging process, especially when confidence is impaired or in particularly stressful

587 situations. Similar to adaptive pre-shot routines (Crews \& Boutcher, 1986), it seems logical

588 to suggest that post-shot routines should also be capable of molding around a host of

589 expected (and unexpected) contexts.

590 In relation to the final aim of this study, the influence of SMMs on player's attention

591 at macro- and meso-levels was apparent throughout the findings. At the macro-level,

592 caddies, coaches, and psychology specialists generally all inputted to course strategy;

593 however, their exact input was mediated by shared team interaction mental models (i.e.,

594 based on a shared understanding of how they needed to work together: Cannon-Bowers et al.,

595 1993). Further, participants revealed that shared team and task models allowed team

596 members (especially the caddie) to develop a preliminary strategy before the player had even

597 arrived at a competition. Once again, this approach worked to manage the player's

598 attentional focus and load leading up to and then within their performance. During

599 performance itself, participants noted how caddies - through shared team member, 
Running head: MACRO AND MESO LEVELS OF GOLF

PERFORMANCE

600

601

602

603

604

605

606

607

608

609

610

611

612

613

614

615

616

617

618

619

620

621

622

623

interaction, and task mental models - supported and influenced golfers' thinking during the pre $^{2}$ and post-shot routines (as well as the other time in between shots and holes). Indeed, through understanding the player's character, the way they played, and the course strategy, caddies often seemed to know what to say and when to say it (Aitken \& Weigand, 2007;

Lavallee, Bruce, \& Gorley, 2004; Simpson et al., 2011). In this case, such expertise helped players to focus their attention on the most appropriate things at the most appropriate time; including dissociating from golf between shots and holes (Aitken \& Weigand, 2007; Simpson et al., 2011; Swann, Piggott, Crust, Keegan, \& Hemmings, 2015).

While providing a number of novel insights, this study was not without its limitations. For example, the acquired perceptions may have been susceptible to recall issues and selfpreservation. As we prioritized the development of meaningful rather than generalizable findings from a representative sample, it is also possible that other approaches currently being used by elite golfers were not elicited. Conversely, however, our decision to include support practitioners allowed us to corroborate player accounts, broaden the pool of experience (given that these individuals had worked with multiple high-level players), and better consider the role of SMMs. We also ask the reader to consider other characterizing traits in support of study quality (Sparkes \& Smith, 2009). Specifically, methodological coherence (Mayan, 2009) was aided by using our pragmatic philosophy to inform the identification of practice-oriented research questions, participant selection (i.e., individuals that could provide a range of views on the topic), and data analysis (i.e., a focus on the process of attentional patterning at macro- and meso-levels of elite golf performance: Denzin \& Lincoln, 2008; Giacobbi et al., 2008). Specific strategies for optimizing trustworthiness within our data collection and analysis were also targeted (cf. Methodology section). Finally, as pragmatic study aims to develop novel and useful ways of addressing applied issues (Giacobbi et al., 
Running head: MACRO AND MESO LEVELS OF GOLF

PERFORMANCE

624

625

626

627

628

629

630

631

632

633

634

635

636

637

638

639

640

641

642

643

644

645

646

647

2005), we also ask the reader to consider the “so what?” principle (Bryant, 2009).

Specifically, if our results relate to tangible applied artefacts then what difference do they make to practice-focused theory and consultancy itself?

On this vein - and while all of the themes in Table 1 are practical implications in their own right - this study has stressed the value of proactively addressing macro- and meso-level processes and actions to optimize attentional patterning in elite golf performance (as well as other psychological factors). As suggested by coverage in this paper, preparation of course strategy and structured post-shot and pre $^{2}$-shot routines represent two primary targets. Our findings also offer clear advice on what each of these processes might involve (e.g., a process of reaction, reflection and reasoning, confirmation or revision of mental models, acceptance, and neutralize for the post-shot routine). The role of an elite golfer's support team has also been emphasized, with the development and maintenance of SMMs encouraged; particularly between player and caddie. Of course, the accuracy and efficacy of these recommendations requires empirical validation. Indeed, a useful progression would be to explore the extent to which the themes described by participants in this study are actually engaged by elite golfers and their support teams before and during play; including when they are playing well and not so well. Future work should also delve deeper into the mechanisms of effectively deploying macro- and meso-level processes. For example, the suggestion that golfers should dissociate attention from their performance between shots requires greater exploration. In addition future work should also explore how SMMs in golf are developed and sustained, especially given the logistical (e.g., travel) and cultural (e.g., perfectionist norms) challenges of elite golf.

In conclusion, this study has started the process of filling gaps in our understanding of what elite golfers are and potentially should be attending to outside of their pre-shot routine 
Running head: MACRO AND MESO LEVELS OF GOLF

PERFORMANCE

648 (Davies et al., 2014). Specifically, it is clear that optimal attentional patterning was perceived 649 to be strongly influenced by macro-level preparation, meso-level routines, and support team 650 interactions. As well as generating guidance for practitioners who work in elite golf, we hope 651 that this investigation stimulates further work in an important yet understudied area. 


\section{the Focus and Nature of Player Attention}

\begin{tabular}{|c|c|c|}
\hline & \multicolumn{2}{|l|}{ Impact } \\
\hline Player and/or Support Team Processes and Actions & Impact on the focus and nature of player attention & Impact on other psychological factors \\
\hline 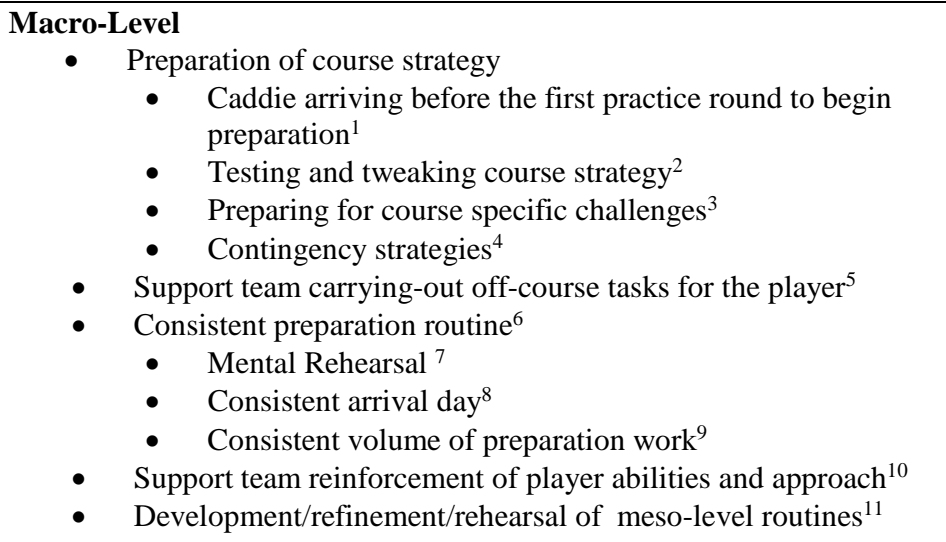 & 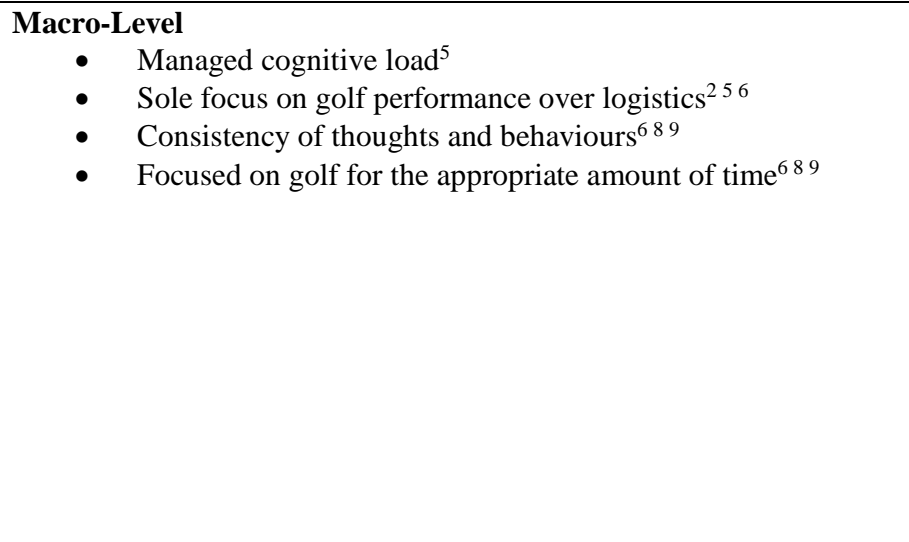 & $\begin{array}{ll}\text { Macro-Level } \\
\text { - } \\
\text { - } & \text { Optimised confidence }{ }^{134710} \\
& 4710 \\
\text { - } & \text { Increased feeling of } \\
& \text { preparedness }^{12346} \\
\text { - } & \text { Decreased chances of mental }^{6} \text { fatigue }^{69}\end{array}$ \\
\hline 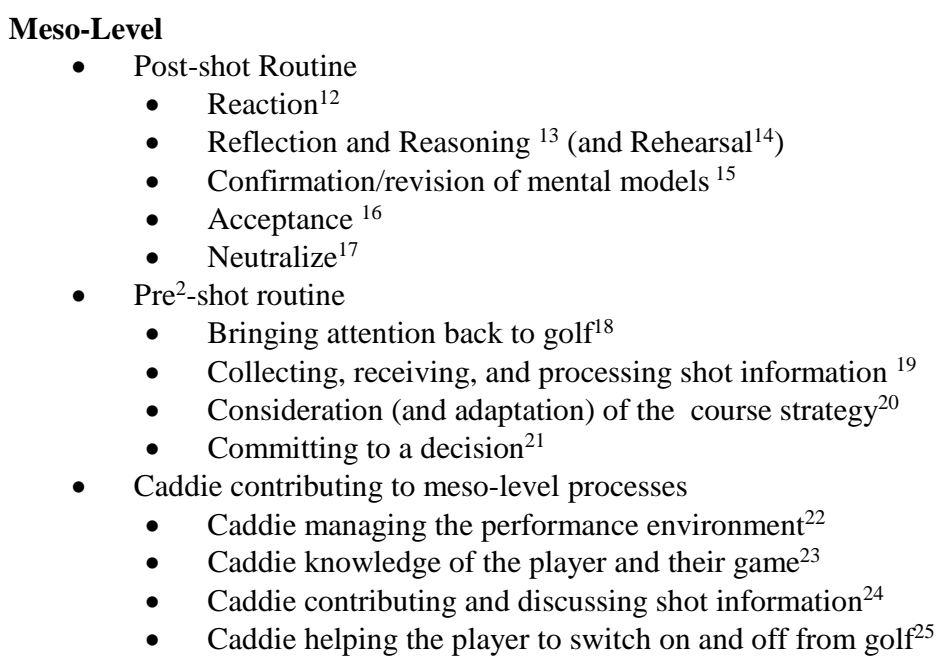 & 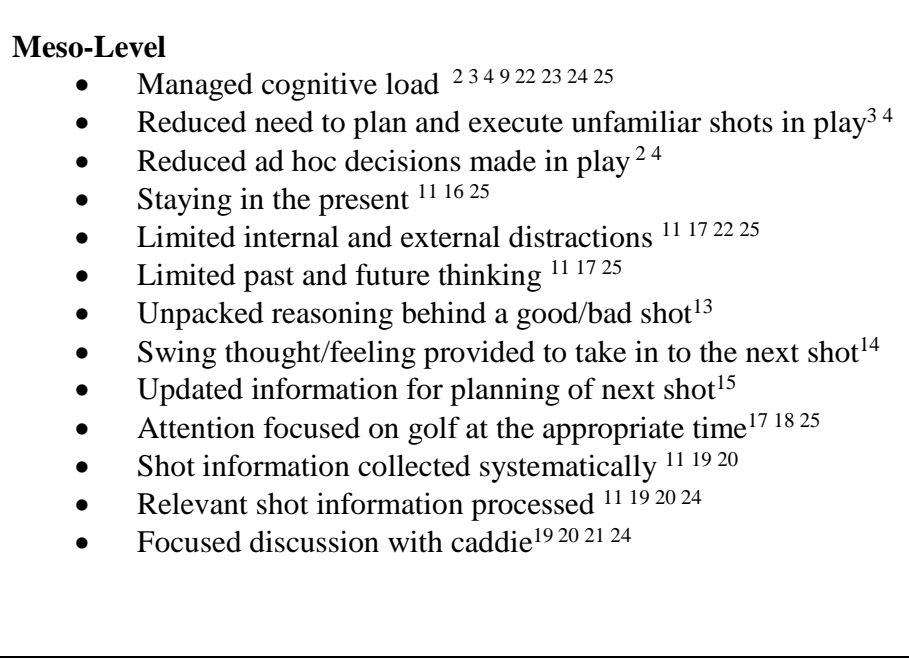 & 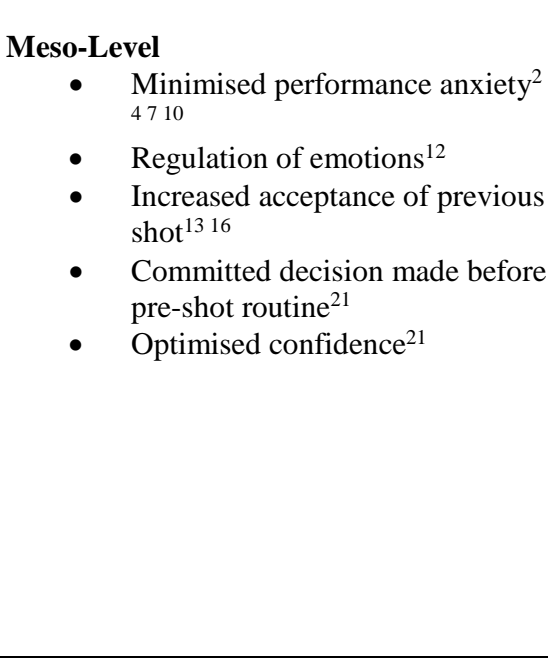 \\
\hline
\end{tabular}


Running head: MACRO AND MESO LEVELS OF GOLF

PERFORMANCE

655

656

657

658

659

660

661

662

663

664

665

666

667

668

669

670

671

672

673

674

675

676

677

678

\section{References}

Aitchison, A., Turner, L. A., Ansley, L., Thompson, K. G., Micklewright, D., \& Gibson, A. S. (2013). Inner dialogue and its relationship to perceived exertion during different running intensities. Perceptual and Motor Skills, 117, 11-30.

Aitken, V., \& Weigand, D. A. (2007). Caddy-talk: Psychology of being a great golf caddy. Milton Keynes: Dawvija Publishing.

Blumenstein, B., \& Lidor, R. (2008). Psychological preparation in the Olympic village: A four-phase approach. International Journal of Sport and Exercise Psychology, 6, 287-300.

Bryant, A. (2009). Grounded theory and pragmatism: the curious case of Anselm Strauss. Qualitative Social Research, 10(3): Art. 2.

Cannon-Bowers, J. A., Salas, E., \& Converse, S. A. (1993). Shared mental models in expert team decision making. In N. J. Castellan, Jr. (Ed.), Current issues in individual and group decision making (pp. 221-246). Hillsdale, NJ: Erlbaum.

Carson, H. J., Collins, D., \& Richards, J. (2014). To hit or not to hit? Examining the similarity between practice and real swings in golf. International Journal of Golf Science, 2, 103-118.

Cohn, P. J. (1991). An exploratory study on peak performance in golf. The Sport Psychologist, 5, 1-14.

Collins, D., \& Cruickshank, A. (2015). The $\mathrm{P}^{7}$ approach to the Olympic challenge: Sharing a practical framework for mission preparation and execution, International Journal of Sport and Exercise Psychology, 13, 21-28.

Corbetta, M., \& Shulman, G. L. (2002). Controls of goal-directed and stimulus-driven attention in the brain. Nature Neuroscience, 3, 201-215. 
Running head: MACRO AND MESO LEVELS OF GOLF

PERFORMANCE

679 Corbin, J. M., \& Strauss, A. (2008). Basics of qualitative research: techniques and procedures for developing grounded theory ( $3^{\text {rd }}$ ed). California: Sage.

681

682

683

684

685

686

687

688

689

690

691

692

693

694

695

696

697

698

699

700

701

702

Côté, J., Salmela, J. H., Baria, A., \& Russell, S. (1993). Organizing and interpreting unstructured qualitative data. The Sport Psychologist, 7, 127-137.

Cotterill, S., \& Collins, D. (2003). Exploring the consistency of pre-shot routines across shottype in golf. In R. Stelter (Ed.), Proceedings of the XIth European Congress of Sport Psychology (pp.45). Copenhagen: Institute of Exercise and Sport Sciences, University of Copenhagen.

Cotterill, S. (2010). Pre-performance routines in sport: Current understandings and future directions. International Review of Sport and Exercise Psychology, 3, 132-153.

Cotterill, S., Sanders, R., \& Collins, D. (2010). Developing effective pre-performance routines in golf: Why don’t we ask the golfer? Journal of Applied Sport Psychology, 22, 51-64.

Crews, D. J., \& Boutcher, S. H. (1986). An exploratory observational behavior analysis of professional golfers during competition. Journal of Sport Behavior, 9, 51-58.

Davies, T., Collins, D., \& Cruickshank, A. (2014). So what do we do with the rest of the day? Going beyond the pre-shot routine in professional golf. International Journal of Golf Science, 2, 163-175.

Denzin, N. K., \& Lincoln, Y. S. (2008). Strategies of qualitative enquiry ( $\left.{ }^{\text {rd }} \mathrm{ed}\right)$. California: Sage.

Eysenck, M. W., Derakshan, N., Santos, R., \& Calvo, M. G. (2007). Anxiety and cognitive performance: Attentional control theory. Emotion, 7, 336-353

Faulkner, G., \& Sparkes, A. (1999). Exercise as therapy for schizophrenia: An ethnographic study. Journal of Sport and Exercise Psychology, 21, 52-69. 
Running head: MACRO AND MESO LEVELS OF GOLF

PERFORMANCE

703

704

705

706

707

708

709

710

711

712

713

714

715

716

717

718

719

720

721

722

723

724

725

Finn, J. (2009). Using mental skills to improve golfing performance: a theory-based case study for golf coaches. Annual Review of Golf Coaching, 4, 223-245.

Friedman, N. P., \& Miyake, A. (2004). The relations among inhibition and interference control functions: A latent-variable analysis. Journal of Experimental Psychology: General, 133, 101-135.

Frost, N. (2011). Qualitative research methods in psychology combining core approaches. Maidenhead: McGraw-Hill.

Garfield, C. A., \& Bennett, H. Z. (1984). Peak Performance: Mental training techniques of the world's greatest athletes. Boston: J P Tarcher.

Giacobbi, P. R., Poczwardowski, A., Hager, P. (2005). A pragmatic research philosophy for applied sport psychology. The Sport Psychologist, 19, 18-31.

Gould, D., \& Maynard, I. (2009). Psychological preparation for the Olympic Games. Journal of Sports Science, 27, 393-408.

Hayslip, B., Petrie, T. A., MacIntire, M. M., \& Jones, G. M. (2010). The influences of skill level, anxiety, and psychological skills use on amateur golfers’ performances. Journal of Applied Sport Psychology, 22, 123-133.

Hellström, J. (2009). Psychological hallmarks of skilled golfers. Sports Medicine, 39, 845855.

Hemmings, B. (2011). Sport psychology and the English Golf Union: A case study of a winter elite squad support programme. Sport and Exercise Psychology Review, 7(1), 34-47.

Hill, D. M., Hanton, S., Matthews, N., \& Fleming, S. (2010). A qualitative exploration of choking in elite golf. Journal of Clinical Sport Psychology, 4, 221-240. 
Running head: MACRO AND MESO LEVELS OF GOLF

PERFORMANCE

Hutchinson, J. C., \& Tenenbaum, G. (2007). Attention focus during physical effort: The mediating role of task intensity. Psychology of Sport and Exercise, 8, 233-245.

Kirschenbaum, D. S. (1997). Mind matters: Seven steps to smarter sport performance. Carmel, IN: Cooper

Kirschenbaum, D. S., Owens, D., \& O’Connor, E. A. (1998). Smart golf: Preliminary evaluation of a simple, yet comprehensive, approach to improving and scoring the mental game. The Sport Psychologist, 12, 271-282.

Lavallee, D., Bruce, D., Gorley, T., \& Lavallee, R. M. (2002). The golfer-caddie partnership: An exploratory investigation in to the role of the caddie. In E. Thain (Ed.), Golf Science IV: The Proceedings of the World Scientific Congress of Golf (pp.284-297). London: Routledge.

Lavallee, D., Bruce, D., \& Gorely, T. (2004). The golfer-caddie partnership: An exploratory investigation into the role of the caddie. Athletic Insight: The Online Journal of Sport Psychology, 6, Retrieved from http://www.athleticinsight.com/Vol6Iss1/GolfCaddieRole.htm

Loehr, J. (1994). The new toughness training for sports. New York: Plume.

Magill, R., \& Anderson, D. (2014). Motor learning and control: Concepts and applications (10 ${ }^{\text {th }}$ ed). New York: McGraw-Hill.

Mayan, M. J. (2009). Essentials of qualitative inquiry. Walnut Creek, CA: Left Coast Press.

McCaffrey, N., \& Orlick, T. (1989). Mental factors related to excellence among top professional golfers. International Journal of Sport Psychology, 20, 256-278.

McCann, P., Lavallee, D., \& Lavallee, R. (2001) The effect of pre-shot routines on golf wedge shot performance. European Journal of Sport Science, 21(5), 231-240. 
Running head: MACRO AND MESO LEVELS OF GOLF

PERFORMANCE

750

751

752

753

754

755

756

757

758

759

760

761

762

763

764

765

766

Mesagno, C., Hill, D. M., \& Larkin, P. (2015). Examining the accuracy and in-game performance effects between pre- and post-performance routines: A mixed methods study. Psychology of Sport and Exercise, 19, 85-94.

Patton, M. (2002). Qualitative research and evaluation methods ( $\left.3^{\text {rd }} \mathrm{ed}\right)$. California: Sage.

Ravizza, K. (1977). Peak experiences in sport. Journal of Humanistic Psychology, 17(4), 3540.

Simpson, D., Bell, R. J., \& Fliipin, K. J. (2011). Caddying is timing: An interview with Joe Skovron PGA Tour caddy. Journal of Excellence, 14, 93-101.

Sparkes, A. C., \& Smith, B. (2009). Judging the quality of qualitative inquiry: Criteology and relativism in action, Psychology of Sport and Exercise, 10, 491-497.

Strean, W. B. (1998). Possibilities for qualitative research in sport psychology. The Sport Psychologist, 12, 333-345.

Swann, C., Piggott, D., Crust, L., Keegan, R., \& Hemmings, B. (2015). Exploring the interactions underlying flow states: A connecting analysis of flow occurrence in European Tour golfers. Psychology of Sport and Exercise, 16, 60-69.

Winter, S., MacPherson, A. C., Collins, D. (2014). To think, or not to think, that is the question. Sport, Exercise, and Performance Psychology, 3, 102-115. 